\title{
Endoplasmic reticulum protein ERp46 in prostate adenocarcinoma
}

\author{
WILHELMINA C.M. DUIVENVOORDEN ${ }^{1,2}$, SARAH N. HOPMANS ${ }^{1}$, \\ RICHARD C. AUSTIN ${ }^{2,3}$ and JEHONATHAN H. PINTHUS ${ }^{1,2}$ \\ ${ }^{1}$ Department of Surgery, Division of Urology, McMaster University, Hamilton, ON L8V 1C3; \\ ${ }^{2}$ Research Institute of St. Joseph's, St. Joseph's Healthcare, Hamilton, ON L8N 4A6; \\ ${ }^{3}$ Department of Medicine, McMaster University, Hamilton, ON L8S 4L8, Canada
}

Received October 21, 2016; Accepted January 31, 2017

DOI: $10.3892 / 01.2017 .5908$

\begin{abstract}
Endoplasmic reticulum (ER) protein ERp46 is a member of the protein disulfide isomerase family of oxidoreductases, which facilitates the reduction of disulfides in proteins and their folding. Accumulation of misfolded proteins has been implicated in cancer. The objectives of the present study were to investigate the role of ERp46 in prostate cancer, its expression and its effects on prostate cancer growth. A tissue microarray with human prostate cancer and normal prostate tissue samples was stained for ERp46 followed by image analysis. Human prostate adenocarcinoma 22Rv1 cells were stably transfected with short hairpin RNA (shRNA) specific for ERp46, a non-effective scrambled control or a plasmid containing full-length human ERp46 cDNA, and cell growth was determined. Subcloned cells were treated with thapsigargin or tunicamycin to induce ER stress and lysates were subjected to western blot analysis for ER stress proteins. Subcutaneous xenografts of parental 22Rv1, ERp46-overexpressing (ERp46+), shERp46 or scrambled control cells were established in male inbred BALB/c nude mice ( $\mathrm{n}=10 /$ group). Tumor growth curves of the xenografts were constructed over a period of 30 days and subsequently the mice were sacrificed and the amount of serum prostate-specific antigen was determined. The results demonstrated increased ERp46 expression levels in prostate cancer tissue samples of Gleason $\geq 7$ compared with normal prostate tissue samples. When ERp46 was stably knocked down using shRNA or overexpressed in prostate carcinoma 22Rv1 cells, tumor growth in vitro and in BALB/c nude mice was inhibited and accelerated, respectively. ERp46 overexpression led to reduced sensitivity to ER stress as indicated by higher half maximal inhibitory concentrations for
\end{abstract}

Correspondence to: Dr Jehonathan H. Pinthus, Department of Surgery, Division of Urology, McMaster University, 711 Concession Street, Hamilton, ON L8V 1C3, Canada

E-mail: pinthusj@hhsc.ca

Key words: prostate carcinoma, thioredoxin, protein disulfide isomerase, endoplasmic reticulum stress tunicamycin and thapsigargin in ERp46+ cells. The shERp46 cells lost the ability to upregulate protein disulfide isomerase following tunicamycin-induced ER stress. The present study suggests a role for ERp46 as a therapeutic target in prostate cancer, given its expression profile in human prostate cancer, and its effect on prostate cancer cell growth.

\section{Introduction}

It has previously been demonstrated in human renal cell carcinoma that the endoplasmic reticulum (ER) protein, ERp46, a member of the protein disulfide isomerase (PDI) family of oxidoreductases (1), is overexpressed in renal cell carcinoma, and increased expression levels of ERp46 may promote renal cell carcinoma growth in vivo (2). ERp46, also known as thioredoxin domain-containing 5, has three thioredoxin-like domains and is a member of the PDI family of oxidoreductases, which includes 19 members that have been described in mammalian ER (1). PDIs are ubiquitous proteins, and their activity facilitates the reduction of disulfides in other proteins by cysteine-disulfide-thiol exchange (1,3). PDIs are important in the determination of protein structure and function and are able to augment protein stability, protect them from damage and increase their half-lives.

The formation of disulfide bonds is reversible and may be a key element in the regulation of protein stability (1). Previously, ERp46 was revealed to interact with adiponectin receptor 1 , leading to decreased activation of adenosine monophosphate-activated protein kinase in HeLa cells (4). ERp46 has a large number of other interacting partners as determined by previous proteomic and interactome studies (5-7); the majority of ERp46 interacting partners are involved in oxidoreductive reactions (5). Although little is known about ERp46's biological function, it has previously been demonstrated to be highly overexpressed in castration-resistant prostate cancer compared with hormone naïve prostate cancer, and was revealed to interact with the androgen receptor in human prostate cancer LNCaP cells, which led to an increase in androgen receptor stability and signaling (8).

Using various methodologies in vitro and in vivo, the present study additionally investigated ERp46 as a potential therapeutic target in prostate cancer (PC) with a focus on 
ERp46-mediated ER stress. The present study demonstrated a significantly increased ERp46 expression level in PC tissue samples with a Gleason score $\geq 7$ compared with normal prostate tissues, and demonstrated that an increased expression level of ERp46 promoted PC growth, at least in part, due to an increased protective mechanism of dealing with ER stress.

\section{Materials and methods}

Patient material and ERp46 immunohistochemistry. A tissue microarray (TMA) with duplicate cores from a total of 57 prostate cancer and 9 normal prostate tissue specimens was obtained from US Biomax (\#PR208; Rockville, MD, USA). Immunohistochemistry for ERp46 was performed as described previously (2). Immunohistochemical staining controls included a human lymph node (positive control) and the omission of primary antibody (negative control). The $\mathrm{H}$-score for the tissue within each core of the TMA was determined as a measure of staining intensity, as described in our previous study (9). For each individual, the adjusted $\mathrm{H}$-score was determined by subtracting the $\mathrm{H}$-score of the negative control and averaging triplicate $\mathrm{H}$-scores.

Strains, plasmids, cell lines and cell culture. Human prostate adenocarcinoma 22Rv1 cells were obtained from the American Type Culture Collection (Mannasas, VA, USA) and were propagated in RPMI-1640 medium (Thermo Fisher Scientific, Inc., Waltham, MA, USA) supplemented with $10 \mathrm{mM}$ 4-(2-hydroxyethyl)-1-piperazineethanesulfonic acid, $1.0 \mathrm{mM}$ sodium pyruvate and $10 \%(\mathrm{v} / \mathrm{v})$ fetal bovine serum (Thermo Fisher Scientific, Inc.). Cells were cultured in a humidified atmosphere at $5 \% \mathrm{CO}_{2}$ and $37^{\circ} \mathrm{C}$. The cells were routinely verified to be mycoplasma-free.

The short hairpin (sh)RNA vector for ERp46 (a pGFP-V-RS plasmid with the ERp46 shRNA sequence as follows: GGT GTGGTCATTGTAAGACTCTGGCTCCT), the non-effective negative scrambled control and the pCMV6-Kan/Neo plasmid containing the full-length cDNA encoding human ERp46 were purchased from Origene Technologies, Inc. (Rockville, MD, USA). Transfection of 22Rv1 cells $\left(4 \times 10^{6}\right)$ was performed using electroporation (Bio-Rad Laboratories, Inc., Mississauga, ON, Canada) with $1.5 \mu \mathrm{g}$ plasmid DNA in $400 \mu \mathrm{l}$ ice-cold PBS, at 1,000 V. Cells stably transfected with shERp46 or scrambled control were selected in the presence of $0.5 \mu \mathrm{g} / \mathrm{ml}$ puromycin, cells transfected with full-length ERp46 were selected in the presence of $1.5 \mathrm{mg} / \mathrm{ml} \mathrm{G} 418$.

Cell growth and survival curves. Cell growth was assessed by quantifying DNA content using the Hoechst-DNA binding assay following 6 days of growth, and cells were seeded at 1,000 cells/well on a 96 -well plate (10). Fluorescence was evaluated using a SpectraMax Gemini plate reader [Molecular Devices LLC, Sunnyvale, CA, USA $\left(\lambda_{\mathrm{exc}}=360 \mathrm{~nm}\right.$; $\lambda_{\mathrm{em}}=460 \mathrm{~nm}$ )]. Doubling times were determined from $\geq 2$ separate experiments performed in 8 repeats (mean \pm standard error of the mean).

For survival curves, subconfluent cells were trypsinized, resuspended and seeded at a density of 5,000 cells/well in a 96-well plate in $100 \mu \mathrm{l}$ fetal bovine serum (FBS)-supplemented RPMI-1,640 medium. Cells were allowed to adhere for $24 \mathrm{~h}$, at which time $200 \mu \mathrm{l}$ fresh medium containing $0.06-60 \mathrm{nM}$ thapsigargin or $0.06-20 \mu \mathrm{g} / \mathrm{ml}$ tunicamycin was added. Stock solutions of tunicamycin (2 mg/ml; Sigma-Aldrich; Merck Millipore, Darmstadt, Germany) and thapsigargin (1 $\mathrm{mM}$, Sigma-Aldrich; Merck Millipore) were prepared in dimethyl sulfoxide, aliquoted and frozen until use. After $24 \mathrm{~h}$, the medium was aspirated and $200 \mu \mathrm{l}$ fresh FBS-supplemented medium was added. Cell survival was assessed by quantifying DNA content using the Hoechst-DNA binding assay after 5 days, as described above.

The fraction of cells affected $\left(f_{a}=1-f_{u}\right)$ for each drug dose was averaged and analyzed using CalcuSyn software version 1.2 (Biosoft, Cambridge, UK). CalcuSyn uses the median-effect principle to determine the potency of each drug, in addition to extrapolating the dose for any given effect (11), according to the following equation: $f_{a} / f_{u}=\left(D / D_{m}\right)^{\mathrm{m}}$, where $D$ is the dose, $D_{m}$ is the dose required to achieve half maximal inhibitory concentration $\left(\mathrm{IC}_{50}\right)$ and $f_{a}$ is the fraction affected by $D$. Median-effect analyses that yielded a linear correlation coefficient $>0.90$ demonstrated that the dose-effect data conformed to the median-effect principle and were included in the analysis.

Western blot analysis. For western blot analyses, subconfluent cells were washed twice with PBS and placed in fresh supplemented medium containing $60 \mathrm{nM}$ thapsigargin or $2.5 \mu \mathrm{g} / \mathrm{ml}$ tunicamycin. Protein lysates $(10-30 \mu \mathrm{g})$ were prepared following 6 and $24 \mathrm{~h}$ treatment, resolved by $10 \%$ SDS-PAGE and transferred onto nitrocellulose membranes. Primary antibodies used were goat anti-ERp46 (dilution, 1:1,000; sc-49660; Santa Cruz Biotechnology, Inc., Dallas, TX, USA), mouse anti-GRP78 (dilution, 1:1,000; \#610979, BD Pharmingen, San Diego, CA, USA) and rabbit anti-PDI antibody (dilution, 1:1,000; \#2446, Cell Signaling Technology, Inc., Danvers, MA, USA). Equal protein loading was verified using mouse $\beta$-actin-specific antibody (A00702; dilution, 1;1,000; GenScript, Piscataway, NJ, USA). Secondary horseradish peroxidase-conjugated antibodies (anti-goat, sc-2378; anti-rabbit, sc-2030; anti-mouse, sc-2031; dilution, 1:1,000; Santa Cruz Biotechnology Inc.) were used. Incubation in primary and secondary antibody was carried out for $2 \mathrm{~h}$ at room temperature in Tris-buffered saline/0.1\% Tween 20. Protein bands were visualized by enhanced chemiluminescence using Pierce ECL substrate (Thermo Fisher Scientific, Inc.) and Amersham Hyperfilm ECL film (GE Healthcare Life Sciences, Chalfont, UK).

Animal studies. The animal studies were performed in strict accordance with the guidelines of the Canadian Council of Animal Care and were reviewed and approved by the McMaster University Animal Research Ethics Board (Hamilton, ON, Canada). All necessary steps were taken to minimize suffering and distress to the mice. Per treatment group, five-week old male inbred BALB/c nude mice (Charles River Laboratories, St. Constant, PQ, Canada) weighing 15-20 g, were randomly divided into groups of ten mice. The mice $(5 \mathrm{mice} / \mathrm{microisolator}$ cage) were kept in an ultraclean room on a 12/12-h-light/dark cycle in a temperature $\left(21-24^{\circ} \mathrm{C}\right)$ and humidity $(35-45 \%)$ controlled environment, with food (\#2918 irradiated Teklad rodent diet; Harlan Laboratories, Mississauga, ON, Canada) 
and water available ad libitum. Each cage contained Alpha-dri bedding and a rubber tube to play/sleep for enrichment.

Parental human prostate carcinoma 22Rv1, ERp46-overexpressing (ERp46+), shERp46 or scrambled control 22Rv1 cells were resuspended at a concentration of $1 \times 10^{7}$ cells/ml (1:1 (v/v) serum-free medium (Matrigel; BD Biosciences, Franklin Lakes, NJ, USA). Cell viability was $>95 \%$ by trypan blue exclusion. Cells $\left(1.5 \times 10^{6}\right.$ cells in $\left.150 \mu \mathrm{l}\right)$ were injected subcutaneously into the right flank of the mouse. In order to assess differences in in vivo tumor growth, the size of the tumors was determined every three days using plastic Vernier calipers and tumor volume was evaluated [as $0.5 \mathrm{x}$ (length $\mathrm{x}$ width $x$ height)]. The mice in all groups were assessed together by alternating the cage order and randomly selecting the mice from each cage. The data were used to construct tumor growth curves. After 35 days, the animals were sacrificed, blood was collected and the tumors dissected and weighed. A portion of the tumor was fixed in formalin and embedded in paraffin, while the other part was snap-frozen in liquid nitrogen. The amount of serum prostate-specific antigen (PSA) was determined using a human PSA ELISA-kit (Abcam, Cambridge, MA, USA).

Immunostaining of $4 \mu \mathrm{m}$-thick tumor xenograft sections for cluster of differentiation 31 (CD31) and subsequent image analysis were performed as previously described by Kleinmann et al (12). As a measure of microvessel density in the tumor tissue, two fields of view at magnification, $\mathrm{x} 7$ with the highest vessel density were selected in order to determine the total cumulative linear endothelial length using the ImageScope software version 12.2.2 (Aperio Technologies, Inc., Vista, CA, USA). The endothelial length (in $\mu \mathrm{m}$ ) was divided by the area of the field of view in $\mathrm{mm}^{2}$.

Statistical analysis. Values are given as the mean $\pm 95 \%$ confidence interval (CI) or standard error of the mean, as indicated. The normally distributed data were analyzed using a two-tailed Student's t-test. $\mathrm{P}<0.05$ was considered to indicate a statistically significant difference. The longitudinal tumor volumes were analyzed using one-way analysis of variance (ANOVA) and Tukey's post-hoc tests. Statistical analyses were performed using MiniTab version 14 (MiniTab Inc., State College, PA, USA).

\section{Results}

ERp46 expression level is increased in clinical specimens of human PC tissues of Gleason score $\geq 7$. Using ERp46-immunohistochemistry on tissue microarrays containing human PC tissue samples of various stages and normal prostate specimens, the present study identified the presence of ERp46 protein in specimens from normal prostate tissue (Fig. 1A) and from prostate carcinoma tissue samples (Fig. 1B). ERp46 staining was prominent in the cytoplasm with a granular pattern indicative of ER staining. Staining was also observed in the nucleus. The negative control, consisting of the omission of primary antibody, did not reveal any background staining (Fig. 1C). The amount of ERp46 protein was quantified by image analysis (H-score; Fig. 1D). Prostate carcinoma tissue samples of Gleason scores of $\leq 6 \mathrm{did}$ not exhibit increased ERp46 staining compared with normal prostate tissue samples, whereas prostatic tumors of Gleason scores 7 or $\geq 8$ demonstrated significantly stronger ERp46 staining compared with normal tissue samples $(\mathrm{P}<0.005$ and $\mathrm{P}=0.02$, respectively).

ERp46 is associated with tumor growth in vitro and in vivo. To investigate the significance of ERp46 expression on PC, stably transfected human prostate adenocarcinoma 22Rv1 subclones were generated. Human PC 22Rv1 cells are androgen-responsive and produce PSA. The 22Rv1 cells stably overexpressing ERp46 were created by transfection with an expression plasmid containing the full-length human ERp46, as was the case for stable ERp46-knockdown (using shRNA specific for ERp46). Overall, the transfected cells expressed $89 \%$ knockdown of ERp46 protein expression (shERp46) or a 4-fold increase in ERp46 protein expression level (ERp46+) compared with the respective control cells (Fig. 2A). The growth rates of the ERp46-manipulated cell lines differed from their corresponding controls. Following 6 days of growth, the number of ERp46+ cells was significantly increased compared with parental 22Rv1 cells (Fig. 2B). The 22Rv1 cells had a determined doubling time of $30.81 \pm 2.71 \mathrm{~h}$, whereas the doubling time of the ERp46+ cells was 29.20 $2.07 \mathrm{~h}$. Conversely, shERp46 cells grew more slowly compared with the scrambled control cells; after 6 days, the number of shERp46 cells was significantly reduced compared with the scrambled control cells (Fig. 2B), with a determined doubling time of $32.20 \pm 1.18$ h vs. $32.75 \pm 1.52$ in shERp46 cells.

The in vivo growth rate of the various ERp46-manipulated subclones of PC 22Rv1 cells was similarly affected following subcutaneous injection into nude mice ( $n=10 /$ group; with a tumor take rate of $100 \%$ ). Subcutaneously growing shERp46 cells demonstrated significantly slower tumor growth $\left[\mathrm{P}<0.0005\right.$ (ANOVA); Fig. 3A]. In addition, ERp46 ${ }^{+}$tumors had a significantly increased tumor volume compared with those from 22Rv1-cell injected mice [P=0.02 (ANOVA); Fig. 3B]. Upon sacrifice, serum PSA values were determined. Serum PSA was significantly reduced in mice injected with shERp46 cells compared with mice injected with scrambled control shRNA-transfected cells $[\mathrm{P}=0.0002$ (Student's t-test); Fig. 3C]. Microarray analysis of RNA isolated from the tumors demonstrated that ERp46 remained overexpressed in the ERp46+-injected mice and reduced in the shERp46-mice at sacrifice, 5 weeks following tumor cell injection (data not shown). Using immunohistochemical staining of the subcutaneous tumors for CD31, an endothelial marker, the present study also demonstrated a decreased amount of microvessels in the shERp46-treated mice (Fig. 3D and E), with a linear microvessel length decrease of $37.1 \%$ compared with scrambled control xenografts $\left(0.84 \pm 0.23\right.$ vs. $1.33 \pm 0.34 \mathrm{~nm} / \mu \mathrm{m}^{2}$; $\mathrm{P}=0.003)$. There was no significant difference in serum PSA values (Fig. 3F) or in the amount of microvessels between the 22Rv1- and ERp46+-injected mice (data not shown).

ERp46 overexpression induces less ER stress. Since ERp46 belongs to the family of protein disulfide isomerases, which are involved in protein folding in the ER, the effects of ER-stress-inducing compounds, tunicamycin and thapsigargin, on GRP78, an ER stress-associated protein, in the various ERp46-expressing subclones were determined (Fig. 4). GRP78 protein expression increased in all subclones 3-8-fold 


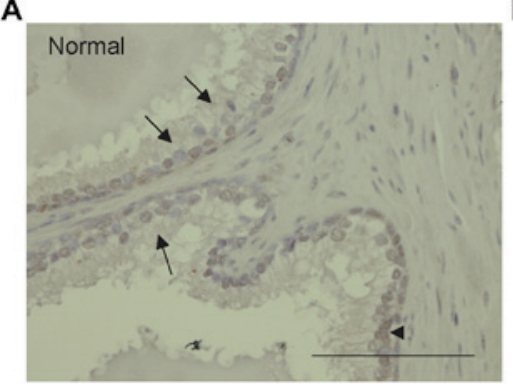

C

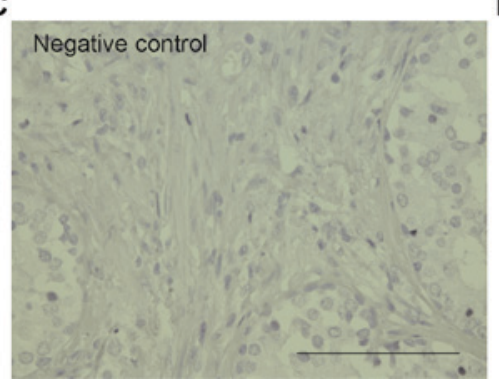

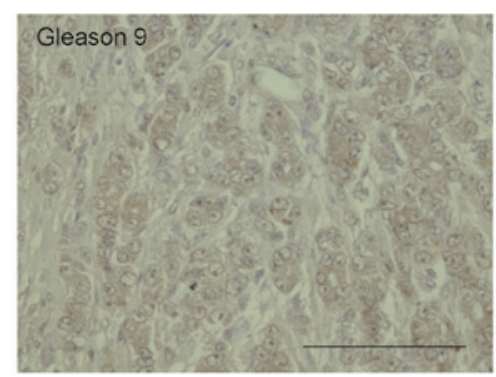

D

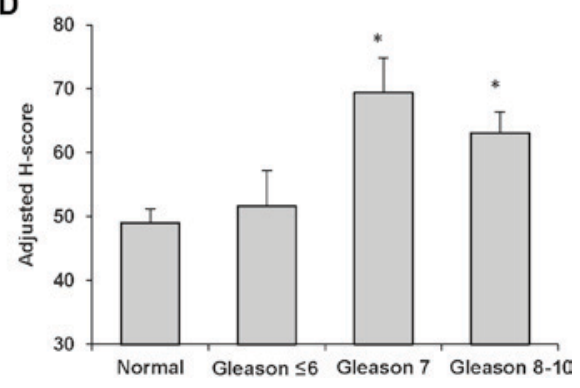

Figure 1. ERp46 expression in human prostate tissues. ERp46 immunohistochemistry of human normal prostate tissues demonstrated (A) granular cytoplasmic staining typical for ER (black arrows), and also nuclear staining (black arrowhead). (B) ERp46 staining of human prostate carcinoma tissues (Gleason score, 9). (C) Negative control (omission of primary antibody). Original magnification, x600. Scale bar=100 $\mu \mathrm{m}$. (D) ERp46 expression level was quantified by image analysis (H-score). The error bars indicate standard error of the mean. " $\mathrm{P}<0.05$, compared with normal prostate tissues. ERp46, endoplasmic reticulum protein 46

A

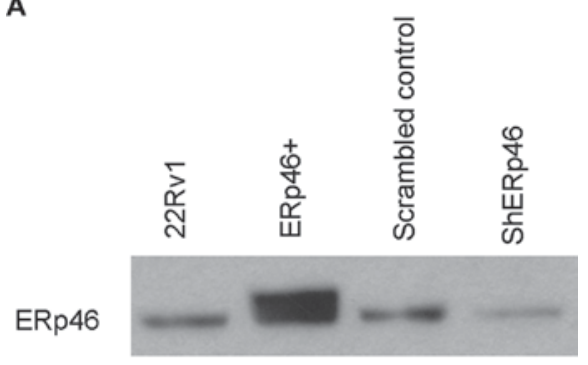

$\beta$-actin
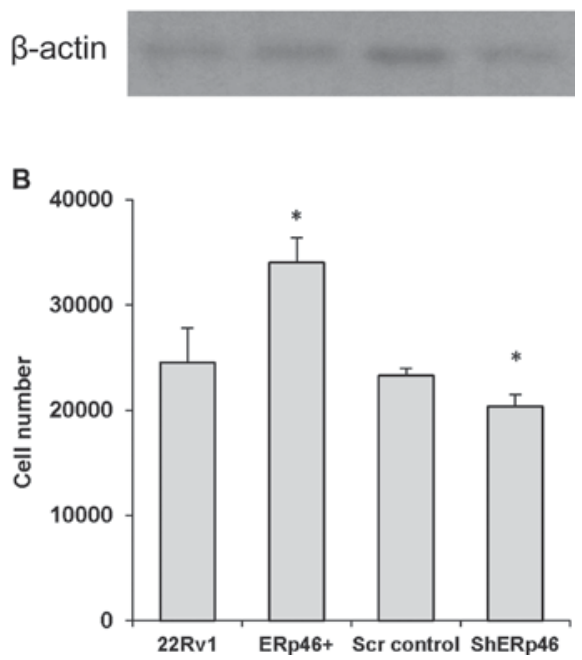

Figure 2. ERp46 supports in vitro tumor growth. (A) ERp46-overexpressing subclone of human PC 22Rv1 cells (ERp46+) demonstrated a 4-fold increase in ERp46 protein, while an 89\% knockdown of ERp46 protein expression was observed in cells stably expressing shRNA specific for ERp46 (shERp46), compared with the corresponding control transfected cells. ERp46 was detected by western blot analysis. The expression level of $\beta$-actin served as a loading control. (B) Cell number of ERp46-manipulated subclones of 22Rv1 following 6 days of growth when seeded at 1,000 cells/well in a 96-well plate. The error bars indicate standard error of the mean. ${ }^{*} \mathrm{P}<0.05$, compared with the corresponding control. PC, prostate cancer; sh, short hairpin; scr, scrambled; ERp46, endoplasmic reticulum protein 46. following $24 \mathrm{~h}$ of treatment with thapsigargin or tunicamycin (Fig. 4). PDI, another member of the protein disulfide isomerase family, was also increased, except in the shERp46 cells treated with tunicamycin where a decrease in PDI protein expression was revealed. The dose-effect relationships for tunicamycin and thapsigargin were also determined via cell survival following a 24-h exposure. The data were subjected to median-effect analysis in order to determine potency $\left(\mathrm{IC}_{50}\right)$ and the linear correlation coefficient (Table I). Overall, ERp46-overexpressing 22Rv1 cells were better able to deal with ER stress. For tunicamyin and thapsigargin, the $\mathrm{IC}_{50}$ was significantly increased in ERp46+ cells compared with the parental 22Rv1 cells. For thapsigargin, the $\mathrm{IC}_{50}$ amounted to $31.54 \mathrm{nM}(95 \%$ CI, 14.78-67.33) in ERp46+ cells vs. $6.98 \mathrm{nM}$ (95\% CI, 5.96-8.16) in 22Rv1 cells, which was a 4.5 -fold increase. For tunicamycin, the $\mathrm{IC}_{50}$ amounted to $0.75 \mu \mathrm{g} / \mathrm{ml}$ (95\% CI, 0.57-0.98) in ERp46+ cells vs. $0.18 \mu \mathrm{g} / \mathrm{ml}$ (95\% CI, 0.07-0.46) in 22Rv1 cells, which was a 4-fold increase.

\section{Discussion}

An increased protein expression level of ERp46 in human metastatic renal cell carcinoma has previously been demonstrated (2), while other studies have demonstrated increased ERp46 protein expression in non-small cell lung carcinoma (13), colorectal adenoma and carcinoma specimens (14), as well as in castration-resistant prostate tumor samples compared with specimens of hormone-naive prostate cancer (8). Similarly, the results of the present study support an association between ERp46 overexpression and prostate cancer aggressiveness. The present study revealed that ERp46 is overexpressed in prostate cancer samples with a Gleason score $\geq 7$, compared with normal prostate tissue samples, and that increased expression of ERp46 promotes PC growth in vitro and in vivo. While the 
A

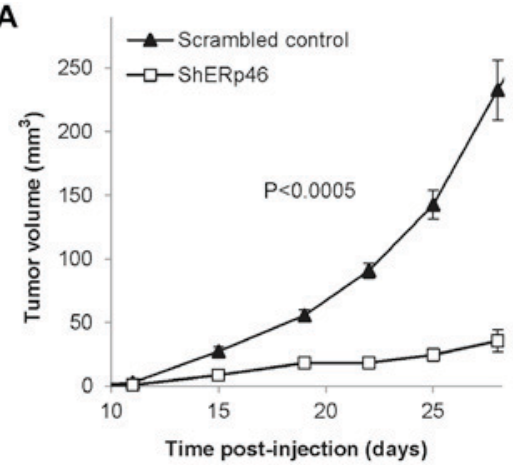

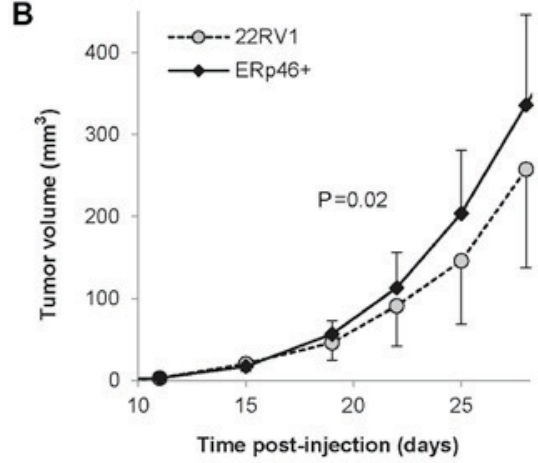

$\mathrm{F}$
C

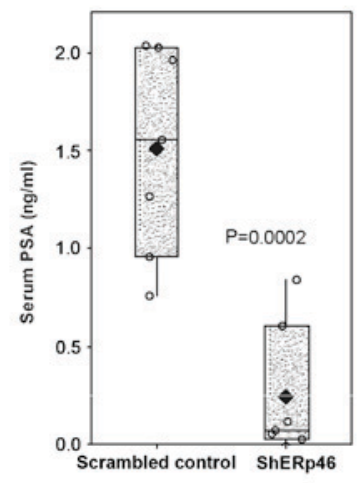

D

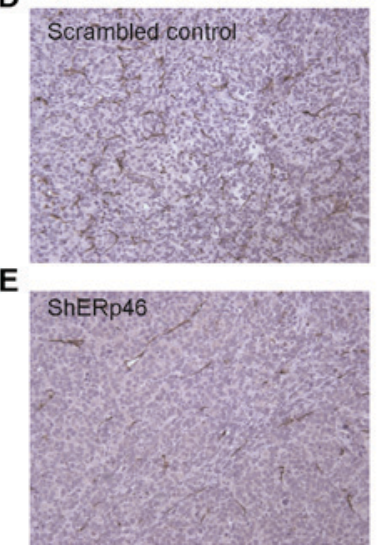

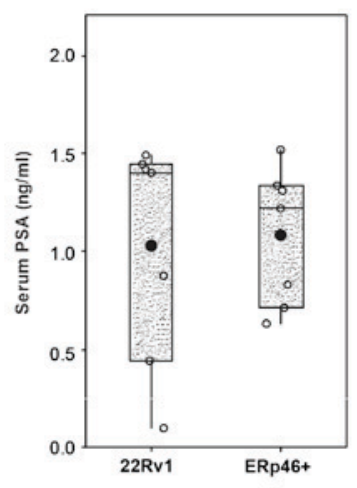

Figure 3. ERp46 supports in vivo tumor growth. (A) Longitudinal tumor growth from mice (n=10/group) subcutaneously injected with shERp46-22Rv1 cells (white squares) was significantly reduced compared with mice injected with cells stably transfected with scrambled control shRNA (black triangles; $\mathrm{P}<0.0005)$. The error bars indicate standard error of the mean. (B) Tumor volume from mice (n=10/group) injected with ERp46+-22Rv1 cells (black diamonds) was significantly increased compared with mice injected with parental 22Rv1 cells (white circles; $\mathrm{P}=0.02$ ). The error bars indicate standard error of the mean. (C) Serum PSA values from mice subcutaneously injected with shERp46-22Rv1 cells were significantly reduced compared with mice injected with cells stably transfected with scrambled control shRNA ( $\mathrm{P}=0.0002)$. Individual values are represented by white circles and the mean by black diamonds; the box indicates the interquartile range. (D) Microvessels as demonstrated by immunohistochemistry of scrambled control 22Rv1 cell xenografts for CD31. Magnification, x400. (E) Immunohistochemistry of shERp46 xenografts for CD31. Magnification, x400. (F) Serum PSA values from mice subcutaneously injected with ERp46-overexpressing 22Rv1 cells compared with parental 22Rv1 cells. Individual values are represented by white circles and the mean by black diamonds; the box indicates the interquartile range. sh, short hairpin; PSA, prostate-specific antigen; CD, cluster of differentiation; ERp46, endoplasmic reticulum protein 46.

differences in doubling times of the subclones in vitro may appear small (1.61 h for ERp46+ vs. 22Rv1 and $0.55 \mathrm{~h}$ for shERp46 vs. scrambled control cells), significant differences in cell numbers were observed following several doubling times. Knockdown of ERp46 demonstrated more significant results on tumor growth in vivo compared with overexpression, which may be due to an already robust expression level of ERp46 in the parental cells. Similar to the results of the present study, ERp46 overexpression also induced an increased tumor cell growth rate in human prostate adenocarcinoma LNCaP cells, in vitro and in vivo (8). This was revealed to be at least in part due to increased androgen receptor stability and signaling in the presence of increased ERp46 (8). Accordingly, in the in vivo experiments of the present study, a significant reduction of PSA secretion, a potential indication of tumor volume, was identified following knockdown of ERp46 (Fig. 3C); however, no significant alterations in PSA secretion by tumors overexpressing ERp46 were observed, which may be due to a sufficient innate ERp46 expression level of the parental cells.

In the present study, a further potential pro-tumorigenic mechanism underlying ERp46 in tumor cells and its involvement in ER stress was investigated. Tumor cells adapt to ER stress, defined by the accumulation of unfolded or misfolded proteins within the ER, by intracellular signaling pathways, which are collectively known as the unfolded protein response (15). The unfolded protein response is initiated by GRP78, an ER chaperone; transcriptional activation of GRP78 results in an upregulation of genes encoding proteins that assist in protein folding, maturation and degradation (15). Human prostate cancer cells express significantly more GRP78 compared with normal prostate epithelial cells, and GRP78 overexpression correlates with recurrence and poor survival (16). The ability to activate the unfolded protein response has been linked to prostate tumorigenesis and cancer progression, as prostate-specific deletion of GRP78 in phosphatase and tensin homolog-deficient mice has been demonstrated to inhibit prostate tumorigenesis (17).

The present study demonstrated that the $\mathrm{IC}_{50}$ for tunicamycin and thapsigargin was increased by $\sim 4$-fold in ERp46-overexpressing cells compared with the $\mathrm{IC}_{50}$ in the other cell lines, indicating that the ERp46+ cells were less sensitive to ER stress. However, GRP78 protein expression increased to a similar extent in all cells following induction of ER stress. Similar to the results of the present study, 
Table I. Dose-effect analysis following treatment of the ERp46-manipulated human prostate cancer 22Rv1 cells with ER stress-inducing agents for $24 \mathrm{~h}$.

\begin{tabular}{|c|c|c|c|c|}
\hline \multirow[b]{2}{*}{ Cell line } & \multicolumn{2}{|c|}{ Thapsigargin } & \multicolumn{2}{|c|}{ Tunicamycin } \\
\hline & $\mathrm{IC}_{50}(95 \% \mathrm{CI}), \mathrm{nM}$ & $r$ & $\mathrm{IC}_{50}(95 \% \mathrm{CI}), \mu \mathrm{g} / \mathrm{ml}$ & $r$ \\
\hline 22Rv1 & $6.98(5.96-8.16)$ & 0.99 & $0.18(0.07-0.46)$ & 0.91 \\
\hline ERp46+ & $31.54(14.78-67.33)$ & 0.98 & $0.75(0.57-0.98)$ & 0.99 \\
\hline Scrambled control & $2.62(1.43-4.80)$ & 0.99 & $0.29(0.16-0.51)$ & 0.94 \\
\hline shERp46 & $5.46(1.58-18.84)$ & 0.95 & $0.36(0.14-0.92)$ & 0.91 \\
\hline
\end{tabular}

Median-effect analysis was performed using the mean survival data obtained from three separate experiments. The linear correlation coefficient, $r$, was determined. ERp46, endoplasmic reticulum protein 46 ; $\mathrm{IC}_{50}$, half maximal inhibitory concentration; sh, short hairpin; CI, confidence interval.

A

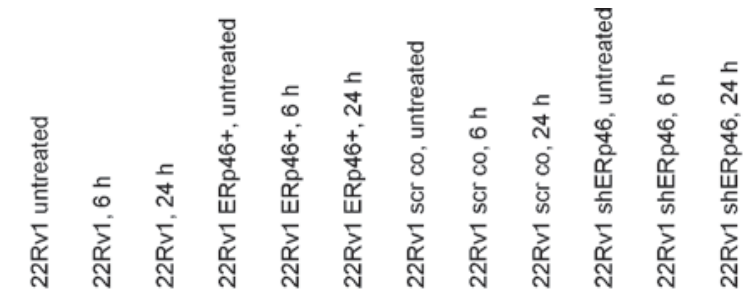

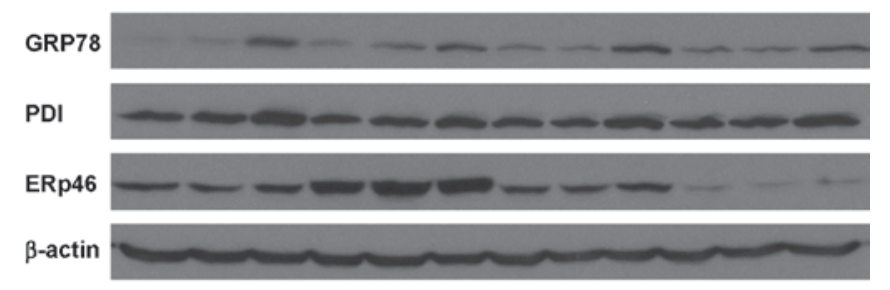

B

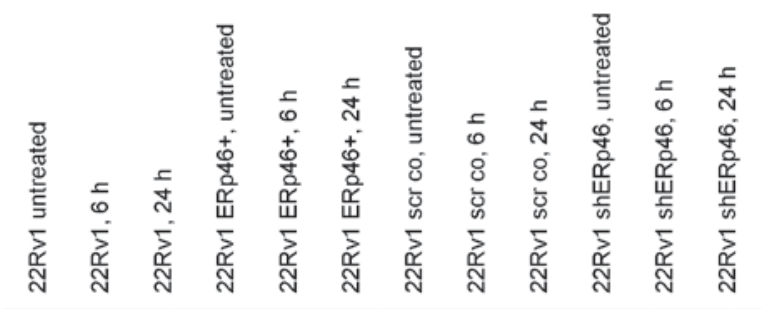

\section{GRP78}

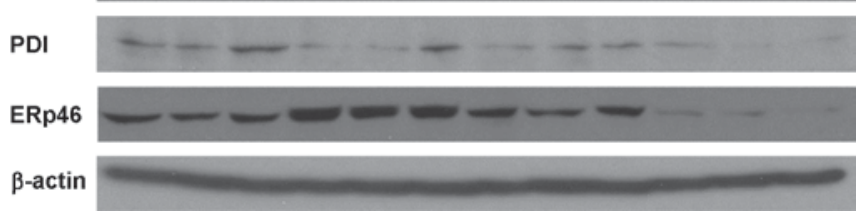

Figure 4. Treatment of shERp46-expressing cells with tunicamycin does not lead to an increase in PDI. (A) ERp46, GRP78 and PDI protein expression levels in ERp46-manipulated 22Rv1 cells following thapsigargin (60 nM) treatment for 6 and $24 \mathrm{~h}$ as determined by western blot analysis. (B) ERp46, GRP78 and PDI protein expression levels in ERp46-manipulated 22Rv1 cells following tunicamycin $(2.5 \mu \mathrm{g} / \mathrm{ml})$ treatment for 6 and $24 \mathrm{~h}$. The expression levels of $\beta$-actin served as the loading control. sh, short hairpin; PDI, protein disulfide isomerase; scr co, scrambled control; ERp46, endoplasmic reticulum protein 46 .

$50 \mathrm{nM}$ thapsigargin also induced an increase in GRP78 in human prostate cancer PC-3 cells after just $6 \mathrm{~h}$ of treatment, in a previous study (18). The results of the present study also demonstrated that PDI, a member of the protein disulfide isomerase family as ERp46 is, does not appear to compensate for ERp46, as all different subclones expressed similar basal PDI levels. PDI protein expression levels also increased with ER stress in all four subclones, except in the shERp46 cells treated with tunicamycin, where a decrease in PDI protein expression level was observed. In neuroblastoma cells, PDI expression is upregulated by tunicamycin and hypoxia (19), and inhibiting PDI activity sensitizes cells to stress-induced apoptosis (20). The data of the present study may indicate that shERp46 cells have lost the ability to upregulate PDI upon ER stress, which may explain the decreased cell growth in vitro and in vivo.

In vivo, knockdown of ERp46 induced a significant overall decrease in tumor volume, with a mean reduction of $74 \%$ between 15 and 28 days following cell injection, an effect comparable to chemotherapeutic drugs, including docetaxol $(7.5 \mathrm{mg} / \mathrm{kg})$ or cisplatin $(5 \mathrm{mg} / \mathrm{kg})$ in $22 \mathrm{Rv} 1$-bearing mice $(21)$. While targeting ERp46 alone may not be effective at slowing tumor growth in the long-term, combining inhibition of ERp46 with docetaxol or cisplatin treatment may be a potential strategy to maximally inhibit numerous growth pathways and yield synergistic effects (21). Indeed, in vitro sensitization to docetaxol has been demonstrated for another ER stress inducer, methylseleninic acid (18). Targeting ERp46 may therefore potentiate the effect of chemotherapy in prostate cancer.

\section{Acknowledgements}

The authors thank Ms. Stephanie Fedorov (McMaster University, Hamilton, ON, Canada) for the technical assistance provided. The present study was supported by a McMaster Surgical Associates basic research grant and Prostate Cancer Canada (pilot grant \#2011-709).

\section{References}

1. Hatahet F and Ruddock LW: Protein disulfide isomerase: A critical evaluation of its function in disulfide bond formation. Antioxid Redox Signal 11: 2807-2850, 2009.

2. Duivenvoorden WC, Paschos A, Hopmans SN, Austin RC and Pinthus JH: Endoplasmic reticulum protein ERp46 in renal cell carcinoma. PLoS One 9: e90389, 2014. 
3. Benham AM: The protein disulfide isomerase family: Key players in health and disease. Antioxid Redox Signal 16: 781-789, 2012.

4. Charlton HK, Webster J, Kruger S, Simpson F, Richards AA and Whitehead JP: ERp46 binds to AdipoR1, but not AdipoR2, and modulates adiponectin signalling. Biochem Biophys Res Commun 392: 234-239, 2010.

5. Jessop CE, Watkins RH, Simmons JJ, Tasab M and Bulleid NJ: Protein disulphide isomerase family members show distinct substrate specificity: P5 is targeted to BiP client proteins. J Cell Sci 122: 4287-4295, 2009.

6. Havugimana PC, Hart GT, Nepusz T, Yang H, Turinsky AL, Li Z, Wang PI, Boutz DR, Fong V, Phanse S, et al: A census of human soluble protein complexes. Cell 150: 1068-1081, 2012.

7. Kristensen AR, Gsponer J and Foster LJ: A high-throughput approach for measuring temporal changes in the interactome. Nat Methods 9: 907-909, 2012.

8. Wang L, Song G, Chang X, Tan W, Pan J, Zhu X, Liu Z, Qi M, $\mathrm{Yu}$ J and Han B: The role of TXNDC5 in castration-resistant prostate cancer-involvement of androgen receptor signaling pathway. Oncogene 34: 4735-4745, 2015.

9. Duivenvoorden WC, Beatty LK, Lhotak S, Hill B, Mak I, Paulin G, Gallino D, Popovic S, Austin RC and Pinthus JH Underexpression of the tumor suppressor LKB1 in clear cell renal cell carcinoma is common and confers growth advantage in vitro and in vivo. Br J Cancer 108: 327-333, 2013.

10. Rago R, Mitchen J and Wilding G: DNA fluorometric assay in 96-well tissue culture plates using Hoechst 33258 after cell lysis by freezing in distilled water. Anal Biochem 191: 31-34, 1990.

11. Chou TC: Theoretical basis, experimental design and computerized simulation of synergism and antagonism in drug combination studies. Pharmacol Rev 58: 621-681, 2006.

12. Kleinmann N, Duivenvoorden WC, Hopmans SN, Beatty LK, Qiao S, Gallino D, Lhotak S, Daya D, Paschos A, Austin RC and Pinthus JH: Underactivation of the adiponectin-adiponectin receptor 1 axis in clear cell renal cell carcinoma: Implications for progression. Clin Exp Metastasis 31: 169-183, 2014.
13. Vincent EE, Elder DJ, Phillips L, Heesom KJ, Pawade J, Luckett M, Sohail M, May MT, Hetzel MR and Tavaré JM: Overexpression of the TXNDC5 protein in non-small cell lung carcinoma. Anticancer Res 31: 1577-1582, 2011

14. Wang Y, Ma Y, Lü B, Xu E, Huang Q and Lai M: Differential expression of mimecan and thioredoxin domain-containing protein 5 in colorectal adenoma and cancer: A proteomic study. Exp Biol Med (Maywood) 232: 1152-1159, 2007.

15. Harding HP, Calfon M, Urano F, Novoa I and Ron D: Transcriptional and translational control in the mammalian unfolded protein response. Annu Rev Cell Dev Biol 18: 575-599, 2002.

16. Daneshmand S, Quek ML, Lin E, Lee C, Cote RJ, Hawes D, Cai J, Groshen S, Lieskovsky G, Skinner DG, et al: Glucose-regulated protein GRP78 is up-regulated in prostate cancer and correlates with recurrence and survival. Hum Pathol 38: 1547-1552, 2007.

17. Fu Y, Wey S, Wang M, Ye R, Liao CP, Roy-Burman P and Lee AS: Pten null prostate tumorigenesis and AKT activation are blocked by targeted knockout of ER chaperone GRP78/BiP in prostate epithelium. Proc Natl Acad Sci USA 105: 19444-19449, 2008.

18. Wu Y, Fabritius M and Ip C: Chemotherapeutic sensitization by endoplasmic reticulum stress: Increasing the efficacy of taxane against prostate cancer. Cancer Biol Ther 8: 146-152, 2009.

19. Tanaka S, Uehara T and Nomura Y: Up-regulation of protein-disulfide isomerase in response to hypoxia/brain ischemia and its protective effect against apoptotic cell death. J Biol Chem 275: 10388-10393, 2000.

20. Ko HS, Uehara T and Nomura Y: Role of ubiquilin associated with protein-disulfide isomerase in the endoplasmic reticulum in stress-induced apoptotic cell death. J Biol Chem 277: 35386-35392, 2002.

21. Festuccia C, Gravina GL, D'Alessandro AM, Muzi P, Millimaggi D, Dolo V, Ricevuto E, Vicentini C and Bologna M: Azacitidine improves antitumor effects of docetaxel and cisplatin in aggressive prostate cancer models. Endocr Relat Cancer 16: 401-413, 2009. 